\title{
Endothelial cells on the proliferation and expression of intercellular adhesion molecule 1 and interleukin 8 of vascular smooth muscle cells
}

\author{
H.-P. Tang ${ }^{1 *}$, L.-X. Sun ${ }^{2 *}$ and W. Han ${ }^{1 *}$ \\ ${ }^{1}$ Department of Respiratory Medicine, Qingdao Municipal Hospital, \\ Qingdao, Shandong, China \\ ${ }^{2}$ Department of Anesthesiology, Qingdao Municipal Hospital, \\ Qingdao, Shandong, China \\ *These authors contributed equally to this study. \\ Corresponding author: W. Han \\ E-mail: weihancn@yeah.net
}

Genet. Mol. Res. 12 (4): 4363-4370 (2013)

Received October 24, 2012

Accepted June 3, 2013

Published October 10, 2013

DOI http://dx.doi.org/10.4238/2013.October. 10.2

\begin{abstract}
The aim of this study was to investigate the influence of activated endothelial cells on the proliferation and secretion of vascular smooth muscle cells (VSMCs). Cultured lung microvascular endothelial cells were treated with or without tumor necrosis factor alpha (TNF- $\alpha ; 10 \mathrm{ng} / \mathrm{mL}$ ) for $6 \mathrm{~h}$, and the supernatant was collected and filtered. The supernatant with TNF- $\alpha$ was called fluid A, and that without TNF- $\alpha$ was called fluid B. VSMCs were cultured and divided into 3 groups with different media as follows: activated medium [fluid A and Dulbecco's modified Eagle medium (DMEM); activated group], inactivated medium (fluid B and DMEM; inactivated group), and DMEM only (control group) for $24 \mathrm{~h}$. Intercellular adhesion molecule 1 (ICAM-1), interleukin (IL)-8, and IL-6 levels in the supernatant of VSMCs were measured with enzyme-linked immunosorbent assay 0 and $24 \mathrm{~h}$ after grouping. The proliferation of VSMCs was detected with 3-(4,5-dimethylthiazol-2-yl)-2,5-diphenyltetrazolium bromide
\end{abstract}


(MTT) assay. ICAM-1 and IL-8 increased above baseline values in the 3 groups; the maximum increase occurred in activated medium. The optical densities in MTT assay of the activated, inactivated, and control groups was $1.35 \pm 0.11,1.01 \pm 0.09$, and $0.29 \pm 0.01$, respectively, which correlated positively with the initial IL-6 level in the supernatant of the VSMCs $(r=0.63, P<0.05)$. TNF- $\alpha$-activated endothelial cells promote VSMC proliferation and secretion of ICAM-1 and IL-8 by elevating IL-6 release.

Key words: Tumor necrosis factor alpha; Endothelial cells; Interleukin-6; Vascular smooth muscle cell

\section{INTRODUCTION}

Chronic obstructive pulmonary disease (COPD) is the most common disease of chronic airway inflammation. According to estimates by the World Health Organization, the global prevalence and mortality of COPD are increasing annually. COPD will become the 3rd cause of death in 2020 (Global Initiative for Chronic Obstructive Lung Disease, 2010). In addition to structural changes in the airway, pulmonary vascular abnormalities are an important part of the structural changes in COPD. The severe degree of pulmonary hypertension is an independent factor that restricts quality of life and affects the prognosis of patients with COPD (Barbera et al., 2003; Minai et al., 2010).

The chronic hypoxia in COPD was formerly considered the main cause of pulmonary hypertension. However, many studies have found that patients with mild or moderate COPD without hypoxia also display vascular inflammation and remodeling (Barbera et al., 1994; Peinado et al., 1998; Santos et al., 2002). Many researchers have begun to pay attention to the important role of inflammation in the development of pulmonary hypertension (Barbera et al., 2003; Peinado et al., 2008; Minai et al., 2010). Studies have shown that the degree of pulmonary vascular remodeling is related to inflammatory cell infiltration in the small airways. Compared with non-smokers, smokers and COPD patients have increased infiltration of inflammatory cells in pulmonary vascular system, especially $\mathrm{CD}^{+} \mathrm{T}$ lymphocytes rather than neutrophils cells, macrophages, and B lymphocytes, suggesting a link between pulmonary vascular remodeling and vascular inflammation caused by toxic particles (Peinado et al., 1999; Seimetz et al., 2011). Interleukin (IL)-6 is an inflammatory factor secreted by activated endothelial cells and vascular smooth muscle cells. It has wide range of biological activities. Injection of recombinant IL- 6 can lead to pulmonary hypertension in rats, whereas dexamethasone may inhibit monocrotaline-induced pulmonary artery Hypertension formation by reducing IL6, suggesting that increased IL-6 play an important role in pulmonary hypertension (Savale et al., 2009; Steiner et al., 2009).

Other causes of pulmonary hypertension-and the pathological and pathophysiological foundations of COPD pulmonary hypertension-are vasoconstriction, vascular remodeling, and in situ thrombosis. Pulmonary vascular remodeling is the most critical process in pulmonary hypertension development and maintenance (Barbera et al., 2003; Minai et al., 2010). During this process, pulmonary vascular cells display a series of functional and structural changes, including apoptosis of endothelial cells, proliferation of smooth muscle cells, and adventitial fibroblasts. 
Endothelial cell damage may be the starting point of all these changes. Endothelial cell injury induces endothelial cell apoptosis and dysfunction, increases secretion of endothelin-1, decreases nitric oxide formation, and releases various inflammatory mediators, leading to the proliferation of smooth muscle cells, adventitial fibroblast proliferation, wall thickening, stenosis, and vascular remodeling and eventually causing to pulmonary hypertension (Peinado et al., 1998; Santos et al., 2002). Therefore, clarifying the influence of pulmonary vascular endothelial cells on smooth muscle cells is of great significance for the prevention and control of COPD and pulmonary hypertension. Our study aimed to observe the influence of the tumor necrosis factor alpha (TNF- $\alpha$ )stimulated supernatant of endothelial cells on the proliferation of vascular smooth muscle cell and inflammatory cytokine secretion and its relationship with IL-6.

\section{MATERIAL AND METHODS}

We used a human lung microvascular endothelial cell line and a human vascular smooth muscle cell line (Cell Bank, Chinese Academy of Sciences, Beijing), recombinant human TNF- $\alpha$ (Shanghai Hao Ran Biotechnology Co., Ltd. Shanghai), a 3-(4,5-dimethylthiazol-2-yl)-2,5-diphenyltetrazolium bromide (MTT) kit (Han Heng Biotechnology (Shanghai) Co., Ltd. Shanghai), anti-IL-6 monoclonal antibody MQ2-6A3 (BD Bioscience Co., Ltd., NJ), an intercellular adhesion molecule 1 (ICAM-1) enzyme-linked immunosorbent assay (ELISA) kit (Shanghai Shang Hu Biotechnology Co., Ltd. Shanghai), IL-8, and an IL-6 ELISA kit (Shanghai Hua Yi Biotechnology Co., Ltd. Shanghai).

\section{Culture and grouping of lung microvascular endothelial cells}

The human pulmonary microvascular endothelial cells were inoculated at a density of $2.0 \times 10^{5}$ cells $/ \mathrm{mL}$ in A flask and B flask, which containing $10 \%$ fetal bovine serum and Dulbecco's modified Eagle medium (DMEM). Adherent cells were added with $10 \mathrm{ng} / \mathrm{mL}$ TNF- $\alpha$ (A bottle) or without TNF- $\alpha$ (B bottle). The cell culture medium was collected after $24 \mathrm{~h}$ and centrifuged to get the supernatant. ELISA was performed on $0.01 \mathrm{~mL}$ supernatant to detect IL-6 levels. The remaining supernatant was stored at $4^{\circ} \mathrm{C}$ after filtration with a $0.22-\mu \mathrm{m}$ microfiltration membrane. Fluid A was supernatant from bottle A. Fluid B was supernatant from bottle B. Fluid C was DMEM medium containing 10\% fetal bovine serum.

\section{Culture and grouping of vascular smooth muscle cells}

The human vascular smooth muscle cell line was inoculated at a density of $2.0 \times 105$ cells $/ \mathrm{mL}$ in $96-w e l l$ plates. The cells was cultured in serum-free DMEM high-glucose culture fluid overnight until the cells were adherent to the wall. Cells were divided into the following groups: 1) Activated, which contained fluid $A$ and fluid $C$ in a 1:1 ratio;2) Inactivated, which contained fluid B and fluid C in a 1:1 ratio; and 3) control, which contained only fluid C. Each group contained 5 repetitions.

\section{Detection of IL-6, ICAM-1, and IL-8 in the supernatant}

Baseline levels of IL-6, ICAM-1, and IL-8 of the supernatants were detected with 
ELISA immediately (baseline) and $24 \mathrm{~h}$ (end value) after the grouping. The difference between the baseline and end values of ICAM-1 and IL- 8 were calculated.

\section{Cell proliferation detection with MTT}

The human vascular smooth muscle cells were added with $10 \mu \mathrm{L} \mathrm{5g/L} \mathrm{MTT} \mathrm{in} \mathrm{the}$ medium $24 \mathrm{~h}$ after the grouping and incubated for $4 \mathrm{~h}$. At the end of the treatment, $100 \mu \mathrm{L}$ dimethyl sulfoxide (DMSO) was added to each well, followed by gently shaking for $10 \mathrm{~min}$ to achieve complete dissolution. The absorbance was determined at $490 \mathrm{~nm}$. The optical density (OD) values were measured at $570 \mathrm{~nm}$ using a multi-well scanning spectrophotometer.

\section{Statistical analysis}

All data are shown as mean \pm standard deviation. We used SPSS 17.0 for Windows (SPSS Inc., USA) to analyze the data. The between-group differences were variances calculated with single-factor analysis. $\mathrm{P}<0.05$ indicated significance.

\section{RESULTS}

\section{Level of IL-6 in the endothelial cell culture medium}

The level of IL-6 in the activated vascular endothelial cell culture medium with TNF- $\alpha$ was $122.70 \pm 6.30 \mathrm{pg} / \mathrm{mL}$, whereas the level in that without TNF- $\alpha$ was $31.16 \pm 2.94 \mathrm{pg} / \mathrm{mL}$. The difference was significant $(\mathrm{t}=22.807, \mathrm{P}<0.05)$, suggesting that TNF- $\alpha$ can promote IL-6 secretion of endothelial cells.

\section{Proliferation of vascular smooth muscle cells in various groups}

The initial IL-6 levels and cellular MTT values are shown in Table 1. Compared with that in the control group, the cell proliferation capacity was significantly increased in the stimulated group and in that without stimulation, and the value of the former was higher than the latter $(\mathrm{P}<0.05)$, suggesting that the endothelial cells, especially activated endothelial cells, released active substances to promote vascular smooth muscle cell proliferation. The MTT value of the smooth muscle cells was positively correlated with the initial IL-6 levels $(r=0.625, \mathrm{P}<0.05)$.

\begin{tabular}{lcc}
\multicolumn{2}{l}{ Table 1. Level of IL-6 and MTT value (Means \pm SD). } & MTT value \\
\hline Group & Initial IL-6 & $1.349 \pm 0.115^{* \#}$ \\
\hline Stimulation & $61.683 \pm 4.664^{* \#}$ & $1.012 \pm 0.087^{*}$ \\
Non-stimulation & $15.700 \pm 3.576^{*}$ & $0.298 \pm 0.014$ \\
Control & $2.263 \pm 0.605$ &
\end{tabular}

\section{Cytokine levels of vascular smooth muscle cells in the supernatant}

The levels of ICAM-1 and IL-8 in the culture supernatant after 0 and $24 \mathrm{~h}$ are shown 
in Table 2. The levels of ICAM-1 and IL-8 before and after culture in supernatant increased. The increase in ICAM-1 and IL-8 concentrations in the stimulated group was significantly higher than that in the non-stimulation and control groups $(\mathrm{P}<0.05)$.

Table 2. Level of ICAM-1 and IL-8 in the serum of vascular smooth muscle cells (Means \pm SD).

\begin{tabular}{|c|c|c|c|c|c|c|}
\hline \multirow[t]{2}{*}{ Group } & \multicolumn{3}{|c|}{ ICAM-1 $(\mu \mathrm{g} / \mathrm{L})$} & \multicolumn{3}{|c|}{ IL-8 (ng/mL) } \\
\hline & $0 \mathrm{~h}$ & $24 \mathrm{~h}$ & Increase value & $0 \mathrm{~h}$ & $24 \mathrm{~h}$ & Increase value \\
\hline Stimulation & $0.184 \pm 0.011^{\text {*\# }}$ & $0.406 \pm 0.034 * \#$ & $0.222 \pm 0.023^{* \#}$ & $10.03 \pm 0.569^{* \#}$ & $13.026 \pm 0.589^{* \#}$ & $2.996 \pm 0.058^{* \#}$ \\
\hline Non- stimulation & $0.101 \pm 0.006^{*}$ & $0.220 \pm 0.027 *$ & $0.117 \pm 0.019 *$ & $1.234 \pm 0.206^{*}$ & $2.300 \pm 0.288^{*}$ & $0.995 \pm 0.082 *$ \\
\hline Control & $0.078 \pm 0.006$ & $0.148 \pm .024$ & $0.070 \pm 0.018$ & $0.165 \pm 0.032$ & $0.351 \pm 0.049$ & $0.187 \pm 0.021$ \\
\hline
\end{tabular}

*P $<0.05$, verse control group; ${ }^{*} \mathrm{P}<0.05$, verse the group without stimulation.

\section{DISCUSSION}

This study showed that TNF- $\alpha$-activated endothelial cells can stimulate vascular smooth muscle cell proliferation and secretion of ICAM-1 and IL-8, which was related with IL-6. These findings help to improve understanding of the mechanism of pulmonary hypertension in COPD.

In this study, we used TNF- $\alpha$-stimulated the human lung microvascular endothelial cells to imitate vascular endothelial cells in COPD inflammation. In accord with the study of Huang et al. (2009), the apoptosis rate and the IL-6 levels in supernatant were significantly increased in the endothelial cells with TNF- $\alpha$ treatment as the manifestations of COPD in vivo (Valipour et al., 2008). As an important pro-inflammatory cytokine with a variety of biological effects, TNF- $\alpha$ mediated the pathophysiologic processes in many diseases, especially in vascular injury and endothelial dysfunction (Zhang et al., 2009; Sethu and Melendez, 2011). TNF- $\alpha$ can produce a direct cytotoxic effect on endothelial cell via the TNF receptor (TNFR) on the surface of endothelial cells or damage endothelial cell structure through oxidative stress and lipid metabolism. Conversely, injured endothelial cells can also release TNF- $\alpha$, which in turn bring further damage to the cells. All these processes reinforce each other to create a vicious cycle (Churg et al., 2002; Orihara and Matsuda, 2008). It was reported that serum TNF- $\alpha$ was elevated in the patients with pulmonary hypertension and pulmonary thromboembolism secondary to COPD (Fujita et al., 2001). In turn, TNF- $\alpha^{-/}$or TNFR-deficient mice can escape from pulmonary hypertension induced by hypoxia (D'hulst et al., 2006; Wright et al., 2007). Therefore, TNF- $\alpha$ deeply involved in the development of COPD as an important bridge between inflammation and vascular remodeling in airways (Mukhopadhyay et al., 2006).

In recent years, a growing number of studies have focused on the interactions between vascular endothelial cells and vascular smooth muscle cells in pulmonary vascular remodeling, and inflammation is one of the most important mechanisms (Peinado et al., 2008; Mathew, 2010). Inflammation leads to endothelial cell structural damage, secretory dysfunction, and expression disorders, which further affect the proliferation signal of vascular smooth muscle cells and results in an imbalance of proliferation and apoptosis. In this study, we found that vascular endothelial cell stimulation of smooth muscle cell proliferation is related to the amount of IL-6 in the culture medium. IL- 6 is a cytokine with a wide range of biological activities that plays extensive biological roles in the process of inflammation response, damage, vascular disease, and arterial atherosclerosis, among other processes (Golembeski et al., 2005). Through the janus kinase/signal transducers and activators of transcription (JAK/ 
STAT ) signaling pathway, IL-6 promotes the proliferation of vascular smooth muscle cells and the release of monocyte chemotactic factor-1 (Watanabe et al., 2004).

Animal studies have confirmed that IL-6 overexpression alone without hypoxia can lead to the formation of pulmonary hypertension in mice (Steiner et al., 2009; Seimetz et al., 2011), but few studies have examined the role of IL-6 in the formation of COPD pulmonary hypertension. Recent studies have found that patients with pulmonary hypertension and COPD have plasma levels of IL-6 that are is significantly higher than those of COPD patients without pulmonary hypertension, and the levels of plasma IL-6 in COPD patients is positively correlated with average positive airway pressure level $(r=0.39, \mathrm{P}<0.001)$ (Chaouat et al., 2009). Conversely, the polymorphism of the IL-6 gene of COPD patients is related to the development of pulmonary hypertension (Eddahibi et al., 2006). These observations suggest that the increase of IL-6 is the key step in the development of COPD-related pulmonary hypertension, which may also be involved in the interactions between endothelial cells and smooth muscle cells.

During the development of pulmonary hypertension in COPD, the vascular smooth muscle cells convert from the stationary state of the contractile phenotype to the proliferative state of synthesis. The extracellular matrix (collagen and elastin) of vascular smooth muscle cells was aggrandized along with increased cytokines and inflammatory factors releasing from them. So in this process, vascular smooth muscle cells were not just structural cells but pluripotent cells in pulmonary vascular remodeling (Noureddine et al., 2011). In this study, we discovered that ICAM-1 and IL-8 produced by the vascular smooth muscle cells were increased after simulation of endothelial cells. As a cell adhesion molecule, ICAM-1 is found on the surfaces of a variety of cells, such as endothelial cells, smooth muscle cells, white blood cells, and it plays an important role in the maintenance of organizational structure, migratory movement of cells, immune regulation, inflammation, and damage repair. ICAM-1 was released rarely from normal endothelial cell but amplified when endothelial cells impaired or stimulated to mediates inflammatory cells adhesion and lymphocytes aggregation. (Rauch et al., 2007). IL-8 is a chemokine found in neutrophils, basophils, $\mathrm{T}$ lymphocytes and other cells that promotes the secretion of inflammatory mediators and adhesion molecules and participates in inflammation by raising the free calcium concentration between cells and increasing the adhesion of cells and the infiltration of local neutrophils (Orr et al., 2010). In COPD, ICAM-I and IL-8 were up-regulated to promote the adhesion and migration of monocytes and lymphocytes to endothelial cells and to induce neutrophils and eosinophils morphological changes, degranulation and aggregation by multiple intracellular signal transduction pathways. Besides aggravating inflammation, ICAM-I and IL-8 also accelerated the process of pulmonary vascular remodeling in COPD (Li et al., 2003; Gosens et al., 2009).

In conclusion, this study confirmed that TNF- $\alpha$ promotes the interaction of vascular endothelial cells and vascular smooth muscle cells and the roles of IL-6. These results provide new research directions for the treatment of COPD-related pulmonary hypertension. However, since IL-6 is a multifunctional cytokine, its antagonization may lead to a very wide range of consequences or even cause serious adverse reactions (Murakami and Nishimoto, 2011). Therefore, the development of organ-specific antagonists of IL-6 will be the focus of future research.

\section{REFERENCES}

Barbera JA, Riverola A, Roca J, Ramirez J, et al. (1994). Pulmonary vascular abnormalities and ventilation-perfusion relationships in mild chronic obstructive pulmonary disease. Am. J. Respir. Crit. Care Med. 149: 423-429. 
Barbera JA, Peinado VI and Santos S (2003). Pulmonary hypertension in chronic obstructive pulmonary disease. Eur. Respir. J. 21: 892-905.

Chaouat A, Savale L, Chouaid C, Tu L, et al. (2009). Role for interleukin-6 in COPD-related pulmonary hypertension. Chest 136: 678-687.

Churg A, Dai J, Tai H, Xie C, et al. (2002). Tumor necrosis factor-alpha is central to acute cigarette smoke-induced inflammation and connective tissue breakdown. Am. J. Respir. Crit. Care Med. 166: 849-854.

D’hulst AI, Bracke KR, Maes T, De Bleecker JL, et al. (2006). Role of tumour necrosis factor-alpha receptor p75 in cigarette smoke-induced pulmonary inflammation and emphysema. Eur. Respir. J. 28: 102-112.

Eddahibi S, Chaouat A, Tu L, Chouaid C, et al. (2006). Interleukin-6 gene polymorphism confers susceptibility to pulmonary hypertension in chronic obstructive pulmonary disease. Proc. Am. Thorac. Soc. 3: 475-476.

Fujita M, Shannon JM, Irvin CG, Fagan KA, et al. (2001). Overexpression of tumor necrosis factor- $\alpha$ produces an increase in lung volumes and pulmonary hypertension. Am. J. Physiol. Lung. Cell. Mol. Physiol. 280: L39-L49.

Global Initiative for Chronic Obstructive Lung Disease (2010). Global Strategy for the Diagnosis, Management, and Prevention of Chronic Obstructive Pulmonary Disease. Update 2010. Available at [http://www.goldcopd.org/ Guidelines/guideline-2010-gold-report.html]. Accessed August 19, 2010.

Golembeski SM, West J, Tada Y and Fagan KA (2005). Interleukin-6 causes mild pulmonary hypertension and augments hypoxia-induced pulmonary hypertension in mice. Chest 128 : 572S-573S.

Gosens R, Rieks D, Meurs H, Ninaber DK, et al. (2009). Muscarinic M3 receptor stimulation increases cigarette smokeinduced IL-8 secretion by human airway smooth muscle cells. Eur. Respir. J. 34: 1436-1443.

Huang NL, Chiang SH, Hsueh CH, Liang YJ, et al. (2009). Metformin inhibits TNF- $\alpha$-induced IкB kinase phosphorylation, IкB- $\alpha$ degradation and IL-6 production in endothelial cells through PI3K-dependent AMPK phosphorylation. Int. J. Cardiol. 134: 169-175.

Li P, Oparil S, Sun JZ, Thompson JA, et al. (2003). Fibroblast growth factor mediates hypoxia-induced endothelin - a receptor expression in lung artery smooth muscle cells. J. Appl. Physiol. 95: 643-651.

Mathew R (2010). Inflammation and pulmonary hypertension. Cardiol. Rev. 18: 67-72.

Minai OA, Chaouat A and Adnot S (2010). Pulmonary hypertension in COPD: epidemiology, significance, and management: pulmonary vascular disease: the global perspective. Chest 137: 39S-51S.

Mukhopadhyay S, Hoidal JR and Mukherjee TK (2006). Role of TNF $\alpha$ in pulmonary pathophysiology. Respir. Res. 7: 125.

Murakami M and Nishimoto N (2011). The value of blocking IL-6 outside of rheumatoid arthritis: current perspective. Curr. Opin. Rheumatol. 23: 273-277.

Noureddine H, Gary-Bobo G, Alifano M, Marcos E, et al. (2011). Pulmonary artery smooth muscle cell senescence is a pathogenic mechanism for pulmonary hypertension in chronic lung disease. Circ. Res. 109: 543-553.

Orihara K and Matsuda A (2008). Pathophysiological roles of microvascular alterations in pulmonary inflammatory diseases: possible implications of tumor necrosis factor-alpha and CXC chemokines. Int. J. Chron. Obstruct. Pulmon. Dis. 3: 619-627.

Orr AW, Hastings NE, Blackman BR and Wamhoff BR (2010). Complex regulation and function of the inflammatory smooth muscle cell phenotype in atherosclerosis. J. Vasc. Res. 47: 168-180.

Peinado VI, Barbera JA, Ramirez J, Gomez FP, et al. (1998). Endothelial dysfunction in pulmonary arteries of patients with mild COPD. Am. J. Physiol. 274: L908-L913.

Peinado VI, Barbera JA, Abate P, Ramirez J, et al. (1999). Inflammatory reaction in pulmonary muscular arteries of patients with mild chronic obstructive pulmonary disease. Am. J. Respir. Crit. Care Med. 159: 1605-1611.

Peinado VI, Pizarro S and Barbera JA (2008). Pulmonary vascular involvement in COPD. Chest 134: 808-814.

Rauch BH, Muschenborn B, Braun M, Weber AA, et al. (2007). ICAM-1 and p38 MAPK mediate fibrinogen-induced migration of human vascular smooth muscle cells. Eur. J. Pharmacol. 577: 54-57.

Santos S, Peinado VI, Ramirez J, Melgosa T, et al. (2002). Characterization of pulmonary vascular remodelling in smokers and patients with mild COPD. Eur. Respir. J 19: 632-638.

Savale L, Tu L, Rideau D, Izziki M, et al. (2009). Impact of interleukin-6 on hypoxia-induced pulmonary hypertension and lung inflammation in mice. Respir. Res. 10: 6.

Seimetz M, Parajuli N, Pichl A, Veit F, et al. (2011). Inducible NOS inhibition reverses tobacco-smoke-induced emphysema and pulmonary hypertension in mice. Cell 147: 293-305.

Sethu S and Melendez AJ (2011). New developments on the TNF $\alpha$-mediated signalling pathways. Biosci. Rep. 31: 63-76.

Steiner MK, Syrkina OL, Kolliputi N, Mark EJ, et al. (2009). Interleukin-6 overexpression induces pulmonary hypertension. Circ. Res. 104: 236-244.

Valipour A, Schreder M, Wolzt M, Saliba S, et al. (2008). Circulating vascular endothelial growth factor and systemic inflammatory markers in patients with stable and exacerbated chronic obstructive pulmonary disease. Clin. Sci. 115: 225-232. 
Watanabe S, Mu W, Kahn A, Jing N, et al. (2004). Role of JAK/STAT pathway in IL-6-induced activation of vascular smooth muscle cells. Am. J. Nephrol. 24: 387-392.

Wright JL, Tai H, Wang R, Wang X, et al. (2007). Cigarette smoke upregulates pulmonary vascular matrix metalloproteinases via TNF-alpha signaling. Am. J. Physiol. Lung Cell. Mol. Physiol. 292: L125-L133.

Zhang H, Park Y, Wu J, Chen X, et al. (2009). Role of TNF-alpha in vascular dysfunction. Clin. Sci 116: 219-230. 